\title{
The doctor and the patient: doing too much or too little
}

\author{
Francesco D'Amore \\ Board member FADOI Foundation, Rome, Italy
}

In his work, the doctor walks a narrow line between doing too much or doing too little. This is a difficult terrain requiring a sense of balance, of solidarity and the knowledge that, in the near future, the doctor will be the main actor in changing the relationships between the medical profession and society.

There is a need, almost a necessity, to provide a comprehensive view of the many aspects that make up the medical profession, the relationship between the doctor and the patient, and the complicated and confusing welfare system. Nardi et al. have interpreted this need with their article Toward a sustainable and wise healthcare approach: potential contributions from hospital Internal Medicine Departments to reducing inappropriate medical spending, published recently in the Italian Journal of Medicine. ${ }^{1}$ They discuss the need to provide tools for wise and efficient clinical methodology: We would like to offer some possible ideas for action on a national level, aimed at a frugal and efficient hospital Internal Medicine approach. ${ }^{1}$ An original functional and valuable model of behavior is needed to deal with the different Italian realities and their problems, situations in which the doctor has to pay for any disservice or inadequacy.

To do this, the doctor must behave in a clear and appropriate way, making his decisions according to evidence-based medicine, consistent with the patient's clinical condition, and the psychological, social, familial and environmental factors involved. Basically, the main risks to be avoided are 2-fold: either too timid an approach which would lead to a general state of ill health in the community, as represented by Romains in Dott. Knock ou Le triomphe de la médicine, ${ }^{2}$ or negligent conduct which would cause more and

Correspondence: Francesco D’Amore, Via Rodolfo Lanciani 2, 00162 Roma, Italy.

Fax: +39.06.3729885

E-mail: dott_damore@libero.it

This work is licensed under a Creative Commons Attribution NonCommercial 3.0 License (CC BY-NC 3.0).

CCopyright F. D'Amore, 2013

Licensee PAGEPress, Italy

Italian Journal of Medicine 2013; 7:135-137

doi:10.4081/itjm.2013.135 harmful damage. Nardi's article includes two interesting chapters, one examining overdiagnosis, and the other professional inertia with the related costs that may arise.

To overcome these attitudes, the internist has perhaps the responsibility to make his voice heard on a cultural and educational level, even though this will be overwhelmed by the deafening outcry produced by the care given to a single organ. Daniel Pennac writes that today's doctor only cares about the cellular puzzle, the X-rayed, US-scanned, CT-scanned, analyzed body, the biological, genetic, and molecular body, the factory of antibodies. ${ }^{3}$

Fragmenting the body like this into several pieces (what Cavicchi calls knowledge through reduction ${ }^{4}$ ) means that advice comes from many different quarters, reinforced by threats of denouncement. Richard M. Plotzker, a US endocrinologist, has defined the excessive use of advice consultorrhea, an explicitly ironic term for a trend that is difficult to contain. ${ }^{5}$ As Plotzker himself writes, it is a trend in the midst of which the doctor could find safer ground in strict clinical reasoning as an integral part of care.

However, besides the many different consultations with specialists, there is still a need for one specialized figure of reference, such as an internist, who can reestablish the personal identity and integrity of the patient and who knows how to identify the clinical priorities and subsequent diagnostic and therapeutic interventions to be made. The internist is aware that his patient is often overwhelmed by the uncertainties created by the fact that biology does not run a linear course. The patient is not just a body, but a collection of hopes, dreams, desires, and personal dignity, and the doctor must be able to perceive the difficulties the patient has to deal with. In the face of the patient's distress, the doctor must be able to offer active and decisive support, also bearing in mind that, as Nardi et al. said, it is not always true that more is better. ${ }^{1}$ On the contrary, if we remember the well-known report of the Journal of the American Medical Association (JAMA), we have to reinforce the concept that less is more by spreading the principle of best care at lower $\operatorname{cost}^{6}$ (a view shared by the US Institute of Medicine).

One of the areas in which doctors themselves should show to be both prepared and sensitive is that of therapeutic reconciliation. This is put to the test at crucial moments such as the admission to the hospital, when the patient is discharged, and when monitoring 
procedures are carried out. These are moments in which the treatment prescribed can be changed according to the clinical condition, safety and compliance of the patient. ${ }^{7}$

Nardi emphasizes that we have to learn (or relearn) to practise medicine in a way that is not so dependent on technology. Our medical healthcare has to be tailored to the real needs of the person. In this way, it will be easier for us to remember that the diagnosis is based, in most cases, on history and physical examination, and that the last drug used is not necessarily the best. ${ }^{1}$ In the US, the American Board for Internal Medicine (ABIM) Foundation proposed the model of choosing wisely. ${ }^{8}$ This was embraced by numerous scientific societies in order to help doctors, patients and their families to select more clinically and economically rational care and treatment strategies. This model focuses on the view of medicine based strictly on method, medicine that is not improvised, nor selfreferential, that is free from constraints and able to determine the priorities of complexity. The Italian Federation of Associations of Hospital Doctors on Internal Medicine (FADOI), with the systematic study of Nardi, wanted to refer to original models of a sustainable hospital Internal Medicine approach, by searching for wise and efficient tools of clinical methodology for our patients. We would like to offer some possible ideas for action on a national level, aimed at a frugal and efficient hospital Internal Medicine approach. A practice that involves useful, selective, effective and wise medical interventions means being able to select priorities and identify the most important of the many complex problems, often overlapping with different sub-specialist situations. The FADOI Ten Points for a Slow Medicine, developed according to shared opinions between Slow Medicine and FADOI scientific societies, provide recommendations for a respectful, sustainable and wise hospital medicine for the Internal Medicine complex patients (Table 1). Basically, FADOI encourages an approach to medicine that keeps the basic features of clinical methodology, starting from the historical reporting and objective data analysis to the function of differential diagnostics. It then proposes the use of all appropriate technological and therapeutic means.

The Ten Points outline a view of medicine that considers the active role of the patients as a fundamental factor in order to achieve the objectives agreed with the doctor, the driving force on the patient's road to care and treatment.

Table 1. The Ten Points of the Federation of Associations of Hospital Doctors on Internal Medicine for a Slow Medicine.

1. In the Internal Medicine complex patient with multi-morbidities you have to exercise a proactive selection of priorities, putting the various problems in order of importance with respect to their actual clinical significance

2. You must not request unnecessary specialist consultations: consultations should be limited to those that are really needed according to the expected results of the individual case

3. Before requesting new tests and examinations you should check: i) if they have already been carried out previously and, if so, when; ii) what additional useful information can they give you concerning patient management; iii) what are the risks involved

4. You have to inform and involve the patient and his caregivers about the choices concerning care; you have to tailor the management and treatment of the patient according to his real needs, values, and preferences, as well as considering potential risks; according to the best available knowledge, you have to explain what clinical goals can be realistically pursued and which potential improper requests could be made by the patient and his family

5. In the terminal patient at the end of life, please refrain from sophisticated and/or invasive procedures. Treatment choice should ensure adequate quality of life and effective pain control

6. At hospital admission, at discharge and at each check up/outpatient visit you have to exercise the concept of medication reconciliation. Reconciliation is the process that starts with comparing the list of drugs taken by the patient (recognition) with those that should be administered to the patient in the particular circumstances at that time. This allows you to decide the correct medication to be prescribed

7. For any new treatment and for treatment-naïve patients you have to use equivalent drugs according to patients' characteristics, the disease and the active ingredients of the drug concerned

8. On discharge from the hospital, reduce the number of prescribed drugs as much as possible, preferably to less than those already being taken before admission

9. Plan the patient's discharge. On admission to the hospital, a comprehensive patient assessment (clinical, functional, psychological-cognitive, economic, social and familial) can help identify difficult to discharge cases, taking into consideration the community health resources available for the continuity of care

10. On hospital discharge, when possible, provide your patients, their families and caregivers with all the information they need for the selfmanagement of the disease: medicines and the equipment or facilities needed, the symptoms and signs to be monitored to maintain patient well-being, the people to contact if help is needed, a list of the procedures and appointments for the post-discharge period, and any home care services that have been activated or that need to be activated. 


\section{References}

1. Nardi R, Berti F, Fabbri L, et al. of the FADOI and Friends in the Appropriate decision making Project Group (FFA-PG) in hospital Internal Medicine wards. Toward a sustainable and wise healthcare approach: potential contributions from hospital Internal Medicine Departments to reducing inappropriate medical spending. Ital J Med 2013:7:65-81.

2. Romains J. Dott. Knock ou Le triomphe de la médicine. Pièce de théâtres. Paris: Comédie des Champs-Élysées; 1923.

3. Pennac D. Storia di un corpo. Milano: Feltrinelli; 2012.

4. Cavicchi I. Ripensare la medicina. Torino: Bollati Boringhieri; 2004

5. Plotzker RM. Where's endocrinology in 'choosing wisely'? excesses in diabetes and endocrinology. Available from: http://www.medscape.com/viewarticle/ 782406

6. The JAMA network. Specialties \& topics, less is more. Available from: http://jamanetwork.com/collection. aspx?categoryID-6017

7. Kwan JL, Lo L, Sampson M, Shojania KG. Medication reconciliation during transitions of care as a patient safety strategy: a systematic review. Ann Intern Med 2013;158:397-403.

8. Volpp KG, Loewenstein G, Asch DA. Choosing wisely. Low-value services, utilization, and patient cost sharing. JAMA 2012;308:1635-6. 